\title{
Electron Microscopic Study of Measles Virus Infection: Cell Fusion and Hemadsorption
}

\author{
RENTIER B, HOOGHE-PETERS E L, DUBOIS-DALCQ M
}

Infectious Diseases Branch, National Institute of Neurological and Communicative Disorders and Stroke, National Institutes of Health, Bethesda, Maryland 20014

Virus-induced cell fusion has been studied after infection of Vero cells with measles virus. Scanning and transmission electron microscopy were combined with immunoperoxidase labeling of measles antigens to correlate viral production and distribution of virus-induced erythrocyte binding sites with progress of fusion-Release of infectious virus started before syncytia were detected and decreased while the number and size of syncytia were increasing. Most virions were seen budding from mononucleated cells or from the periphery of syncytia where cells were being recruited. Moving inward, the surfaces of syncytia were covered with numerous ridges containing viral antigen, but few viral buds were seen, suggesting that syncytia might be sites of defective viral formation.

Hemadsorption occurred predominantly within the confines of syncytia. Erythrocytes were scattered sparsely over immature syncytia but were densely packed in the center of mature syncytia. Active binding sites for erythrocytes were located on cell villi and ridges covered with measles antigens. Hemadsorption was completely inhibited in measles virus-infected cultures pretreated with virusspecific immunoglobulin $\mathrm{G}$ for $1 \mathrm{~h}$ at $4^{\circ} \mathrm{C}$. However, when these cultures were shifted to $37^{\circ} \mathrm{C}$, hemadsorbing sites were recovered at the periphery of enlarging syncytia. Virus-induced sites for erythrocyte adsorption were found to move centripetally on syncytium membranes as fusion progressed.

During infection, important changes occur in membranes of cells infected by ortho- and paramyxoviruses. The plasmalemma acquires viral envelope antigens [17,18] and morphology [3] and the ability to adsorb erythrocytes (RBC) [14, 23]. Hemadsorption (HAD) has been used to study the acquisition of RBC binding sites on membranes of infected cells [23]. This process has been studied extensively by light and transmission electron microscopy (TEM) in cells infected with influenza virus, Newcastle disease virus, pneumonia virus of mice, and mumps and measles viruses $[2,5,10,11,14-16]$. Hemadsorb-ing sites on mumps virus-infected cells also have been studied by scanning electron microscopy (SEM) [15]. Hemadsorbing sites were found on microvilli, on long processes extending from the cell surface, or directly on large areas of infected cell membranes before detection of virusinduced morphological changes. The location, distribution, and structure of hemadsorbing sites on syncytia induced by paramyxovirus infection have not been studied in detail.

Measles virus-infected cells are covered with numerous viral buds and ridges formed by viral surface projections overlying nucleocapsids [9]. In the present study, we combined immunola-

beling of viral antigens with SEM and TEM to study syncytia induced by measles virus infection. The progression of syncytial development from inception through maturation and lysis has been correlated with the distribution of sites of infectious virus production and HAD.

\section{Materials and methods}

Cells and virus. Vero cells, a continuous line of African monkey kidney cells, were grown on 13-mm glass or plastic cover slips in 24-well plates (Cluster 24; Costar, Cambridge, Mass.) as previously described [9]. Measles virus, Edmonston B strain, was plaque purified on Vero cells by W. J. Bellini. Plaque-purified virus was passed twice in Vero cells. The second harvest, containing 5 X $10^{6} \mathrm{PFU} / \mathrm{ml}$, was used in these studies. Confluent monolayers were inoculated at a multiplicity of infection of approximately $0.005 \mathrm{PFU} /$ cell. The virus was adsorbed to cells for $1 \mathrm{~h}$ at $37^{\circ} \mathrm{C}$, the unadsorbed inoculum was removed, and cells were refed with Eagle minimum essential medium (MEM) plus 2\% fetal bovine serum. Cultures were incubated at $37^{\circ} \mathrm{C}$ in an atmosphere of $5 \% \mathrm{CO}_{2}$ in air.

HAD. Before the addition of $1 \%$ rhesus monkey RBC [21], infected Vero cultures were washed extensively with MEM to reduce nonspecific HAD. Adsorption was for $20 \mathrm{~min}$ at $37^{\circ} \mathrm{C}$. It was increased to $60 \mathrm{~min}$ when performed at $4^{\circ} \mathrm{C}$ because hemagglutination by measles virus is less efficient in the cold [19]. Unad-sorbed RBC were removed by several washes with cold MEM, and cultures were either 
fixed directly for electron microscopy or fixed after immunolabeling.

\section{Virus assay}

Over a 7-day period, tissue culture medium from infected cultures was collected daily and stored at $70^{\circ} \mathrm{C}$. The cultures were divided into two groups. The medium was completely replaced daily in one group. In the other group, $0.1 \mathrm{ml}$ of culture medium was removed daily from the 1-ml total and replaced by $0.1 \mathrm{ml}$ of fresh medium. Tenfold dilutions of these samples were inoculated onto confluent Vero monolayers in Costar plates [24 wells]. After adsorption for $1 \mathrm{~h}$ at $37^{\circ} \mathrm{C}$, the cells were overlaid with methylcellulose $(7.5 \mathrm{~g} /$ liter) in MEM plus $2 \%$ fetal calf serum. After 3 days, the methylcellulose medium was removed, the cells were washed, and $1 \% \mathrm{RBC}$ in MEM was added. After $1 \mathrm{~h}$ at $37^{\circ} \mathrm{C}$, unadsorbed RBC were removed by washing, and focal areas with densely packed RBC were counted. This technique gives results in syncytium-forming units because HAD occurs on syncytia. The number of syncytium-forming units in a sample was higher than the number of PFU and appeared to be a more reliable measure of the actual number of infectious units.

\section{Measurement of syncytial surfaces}

The surface area occupied by syncytia was measured in cultures which were also assayed for titers of released virus. The diameter of every syncytium on 13-mm cover slip cultures was measured with an ocular micrometer. Surface area was estimated by assuming that all syncytia are circular.

Measurements were made daily on 20 cover slips and expressed as a percentage of the total surface of the cultures.

\section{Antibodies and immunolabeling}

The immunoglobulin $\mathrm{G}(\operatorname{IgG})$ fraction from a convalescent-phase serum with a measles virus hemagglutination inhibition titer of 1:256 was obtained by precipitation with $50 \%$ ammonium sulfate followed by DEAE chromatography [22]. In HAD inhibition tests, purified $\operatorname{IgG}(0.5 \mathrm{mg} / \mathrm{ml})$ was incubated with cells for $1 \mathrm{~h}$ at $4^{\circ} \mathrm{C}$. Unreacted antibody was removed by washing, and $\mathrm{RBC}$ were added. When cultures were immunolabeled, they were fixed for $5 \mathrm{~min}$ in $1 \%$ paraformaldehyde in 0.1 $\mathrm{M}$ cacodylate buffer, $\mathrm{pH} 7.2$, incubated with protein A coupled to peroxidase for $30 \mathrm{~min}$ at room temperature [8], and reacted for $10 \mathrm{~min}$ at room temperature with the substrate $\left(1 \% \mathrm{H}_{2} \mathrm{O}_{2}\right.$ and $0.5 \%$ diaminobenzi-dine in phosphate-buffered saline) [12].

Enzymes. Cell monolayers were treated for $10 \mathrm{~min}$ at $37^{\circ} \mathrm{C}$ with chymotrypsin (type II, $0.02 \mathrm{mg} / \mathrm{ml}$ ), trypsin (type IX, $0.005 \mathrm{mg} / \mathrm{ml}$ ), bromelain (grade II, $0.01 \mathrm{mg} / \mathrm{ml}$ ), or Pronase (type VI, $0.01 \mathrm{mg} / \mathrm{ml}$ ) in MEM, pH 7.2. All enzymes were obtained from Sigma Chemical Co., St. Louis, Mo. After enzyme treatment, cultures were washed immediately and MEM was added.

TEM. Cultures were fixed in $2 \%$ glutaraldehyde in $0.1 \mathrm{M}$ cacodylate buffer, $\mathrm{pH} \mathrm{7.2,} \mathrm{for} 1 \mathrm{~h}$, postfixed in $1 \%$ osmium tetroxide in the same buffer for $2 \mathrm{~h}$, stained with uranyl acetate at $\mathrm{pH} 5$, progressively dehydrated in ethanol, embedded in Epon, thin sectioned in a plane perpendicular to that of the monolayer, and observed in a Philips 201 transmission electron microscope. Thin sections of immunolabeled cultures were not counterstained with uranyl acetate.

\section{SEM}

Cultures were fixed with glutaraldehyde and osmium tetroxide as described for TEM, progressively dehydrated in methanol, critical-point dried in $\mathrm{CO}_{2}$, coated under high vacuum $\left(<10^{-6}\right.$ torr $)$ with approximately $8 \mathrm{~nm}$ of a gold-palladium alloy, and observed in an ETEC Autoscan field emission scanning electron microscope at a tilt angle of $45^{\circ}$.

\section{Results}

Giant cells 
At the low multiplicities of infection used throughout this study, small syncytia (50 to $100 \mu \mathrm{m}$ ) were first detected in cultures at 2 days postinfection (p.i.). They were scattered over the entire culture and could be studied individually (Fig. 1). At 4 or 5 days p.i., syncytia reached maximum size, with a diameter between 500 and $800 \mu \mathrm{m}$ (mature giant cells). Subsequently, recruitment of cells into syncytia slowed down and stopped. Only a short time elapsed from the mature stage until syncytial lysis began in the center of giant cells and progressed toward the edges, ultimately leading to complete lysis of the giant cell and the formation of a plaque. Sometimes, two or more syncytia fused to form a single plaque. The surface area of cultures occupied by giant cells increased because of secondary infection and concomitant syncytium formation. At 7 days p.i., almost the whole culture consisted of giant cells. The surface area covered by syncytia increased more slowly in cultures completely refed daily than in those not refed during the experiment (Fig. 2).

Infectious virus released from cultures was titrated, and titers were related to the progress of cell fusion. At 24 h p.i., infectious virus was already detected, but syncytia were not seen by light microscopy. Infectivity titers of released virus increased and reached a peak at 5 days p.i. Titers decreased thereafter while the culture area occupied by giant cells continued to increase. Titers of infectious virus from cultures in which the medium was changed daily (see above) were much higher than those from cultures not refed during the experiment. This difference increased progressively each day on the ascending part of the curve (Fig. 2).

At a high magnification with a scanning electron microscope, surface details were revealed on giant cells. The central area of giant cells was covered with twisted strands or ridges (Fig. 3). Their number increased with the size of syncytia. These strands became wider, more twisted, and tightly packed with time, especially in the center of giant cells (Fig. 4). Strands were virtually absent on the edges of giant cells. Close to the central ridges, few viral buds were detected (Fig. 4).

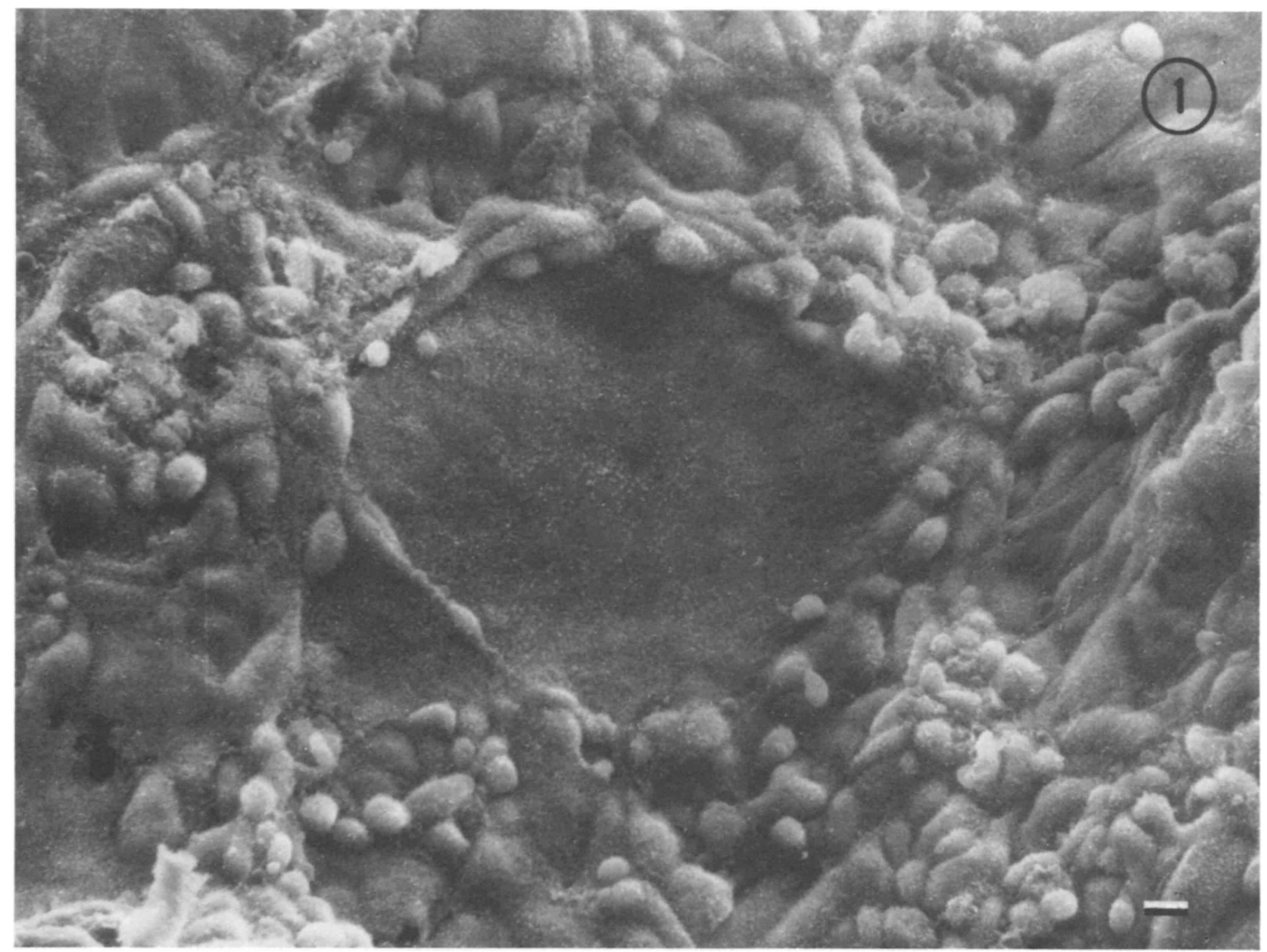

FIG. 1. Low-magnification scanning electron micrograph of a monolayer of Vero cells infected with measles virus at a multiplicity of 0.005 PFU/cell. A typical small syncytium is surrounded by mononucleated cells and covered with small white dots corresponding to scattered villi (see Fig. 3 and 5). Bar $=10 \mu \mathrm{m}$.

Buds were recognized by their size (approximately $400 \mathrm{~nm}$ ) and by coiled strands on the membrane protruding from the cell (Fig. 3). After immunoperoxidase labeling for measles antigen- the reaction product of peroxidase was visualized in a scanning electron microscope as granular material. The size of these granules depended on the reaction time. With a reaction time of $10 \mathrm{~min}$, the size of these granules was approximately 20 to $30 \mathrm{~nm}$. A longer incubation yielded larger granules. Some scattered 
label was seen on flat membrane areas of giant cells, whereas granules were densely packed on ridges (Fig. 5) and viral buds (Fig. 6).

In contrast to giant cells, mononucleated cells surrounding syncytia were covered with numerous viral buds (Fig. 7). Viral buds were recognized by their size, pleomorphic shape, and absence on uninfected cells. Viral buds were also abundant in a narrow band approximately $30 \mu \mathrm{m}$ wide at the periphery of giant cells (Fig. 8).

\section{$H A D$}

$\mathrm{RBC}$ adhering to the monolayer were restricted almost exclusively to giant cells. Mon-onucleated cells adsorbed few RBC (Fig. 9).

After mild treatment of infected cells with chy-motrypsin, mononucleated cells had rounded or detached from the culture surface, while syncytia remained unaltered (a longer treatment was required to detach the giant cells). After chy-motrypsin treatment, HAD still occurred on syncytia, suggesting that RBC binding sites were not altered by this treatment (Fig. 10). Treatment with trypsin, bromelain, or Pronase yielded similar results.

The location of hemadsorbing sites on syncytia was correlated with syncytial size. Hemad-sorbing sites were scattered over the entire surface of small syncytia (Fig. 9). In large syncytia, hemadsorbing sites were clustered in the center. Their outer border was relatively free of hemad-sorbing sites (Fig. 9 and 10). Mature giant cells had a central area with few hemadsorbing sites, but ridges and villi were surrounded by a ring of closely apposed RBC binding sites (Fig. 11 and 12). On degenerating syncytia, the central area was larger and free of hemadsorbing sites, and lysis appeared to begin in this area (Fig. 13).

Structures bearing the hemadsorbing sites were examined by high-resolution SEM and by TEM.

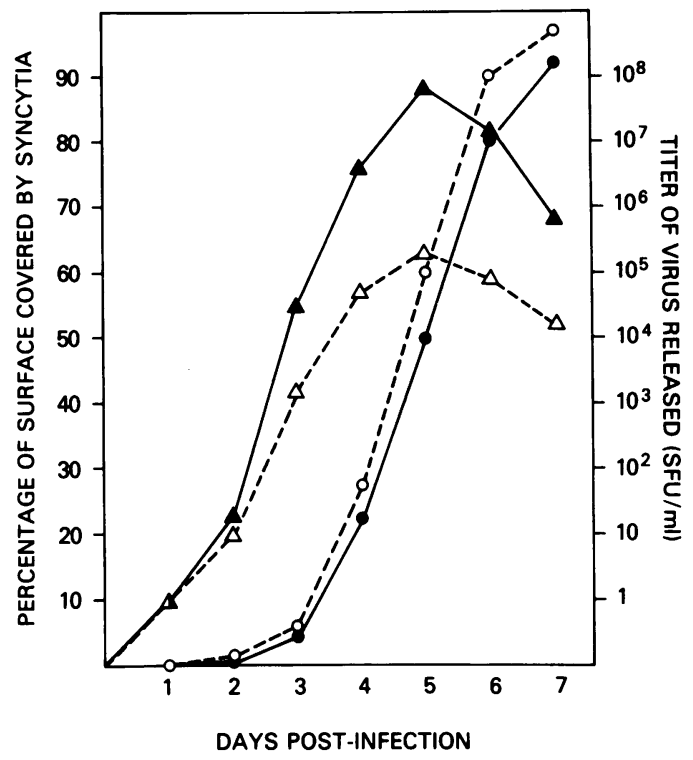

FIG. 2. Comparison of two growth curves showing the titers of measles virus released from Vero cells $(\boldsymbol{\Delta}, \Delta)$ and the percentage of the monolayer surface occupied by giant cells $(\bullet, \mathrm{O})$. These growth curves were established under two different conditions: (i) without changing the medium throughout the experiment (.....); (ii) renewing the culture medium daily

(-). See the text for comments. SFU, Syncytiumforming units.

As seen in thin sections (Fig. 14) and by SEM (Fig. 15), RBC were found in close contact with membrane areas covered with ridges and viral antigen. At a high magnification, viral cap-sids were detected inside these ridges (inset, Fig. 14). SEM also showed attachment of RBC to cell villi (Fig. 16). With TEM, ends of cell villi in contact with RBC were covered with viral antigen (Fig. 14). RBC were rarely found in contact with viral buds. 


\section{Inhibition of $H A D$}

HAD was completely inhibited by pretreatment of infected cells with anti-measles IgG for $1 \mathrm{~h}$ at $4{ }^{\circ} \mathrm{C}$. In contrast, complete inhibition of HAD by antibody was not achieved at room temperature ( 23 to $25^{\circ} \mathrm{C}$ ) or at $37^{\circ} \mathrm{C}$. IgG-treated cells incubated with antibody for $1 \mathrm{~h}$ at $4{ }^{\circ} \mathrm{C}$ and shifted to room temperature for $10 \mathrm{~min}$ regained hemadsorbing sites at the edges of immature syncytia (Fig. 17). However, mature or lytic syncytia did not develop new hemadsorbing sites when treated similarly. New hemadsorbing sites became more numerous on immature syncytia after incubation for longer periods at room temperature or at $37^{\circ} \mathrm{C}$ and were seen closer to the center. After 2 to $4 \mathrm{~h}$, all hemadsorbing sites were clustered in the center of these immature syncytia, as though there had been no antibody treatment.

\section{Discussion}

We have examined the surface of giant cells formed as a result of measles virus infection by low- and high-magnification SEM and by TEM. Morphological events occurring in fusion "from within" [4) have been correlated with the location, density, and mobility of receptors for RBC on syncytia. Measles virus-induced giant cells were found to progress by fusion with cells already infected and to produce few complete virions themselves. In simian virus 5-infected cells, an inverse relationship between the degree of cell fusion and the yield of infectious virus has been found (13). Our observations with measles virus-infected cells provide morphological evidence supporting this observation. Viral buds were present in large numbers on mononucleated cells surrounding syncytia, but were rare on syncytia themselves. Also, the rate of production of infectious virus decreased while the number and surface areas occupied by giant cells were still increasing. The narrow bud-bearing zone at the periphery of giant cells probably contained the plasma membranes of newly incorporated mononuclear cells. Release of buds formed before fusion probably occurred, but new budding sites were not synthesized on the preexisting membrane of giant cells. Membranes of syncytia contained a large number of ridges, consisting of strands of viral surface projections covering nucleocapsids [9). These ridges seemed to accumulate and were rarely incorporated into viral buds, suggesting that a block before budding was present in these areas. Giant cells, therefore, could be considered as sites of defective virus formation during acute productive infection in vitro. A possible analogy is latent infection with subacute sclerosing panencephalitis virus, in which a complete dissociation between viral production and cell fusion has been observed [7].

HAD was found to be an excellent tool for studying measles virus-induced cell fusion. Receptors for HAD appeared to move centripetally while fusion was progressing. Indeed, hemad-sorbing sites were evenly distributed on the surface of small syncytia, but became clustered in the center of enlarging syncytia. This is in contrast to the peripheral distribution of hemad-sorbing sites observed in Newcastle disease virus-infected HeLa cells fused by X-irradiation before infection [16). The pattern of HAD recovery after antibody treatment also supports centripetal movement of $\mathrm{RBC}$ receptors on measles virus-induced giant cells. Hemadsorbing sites reappeared at the periphery of enlarging syncytia. The recovery of HAD sites after antibody treatment occurred as rapidly in our system as in the Newcastle disease virus-infected HeLa system [16]. 

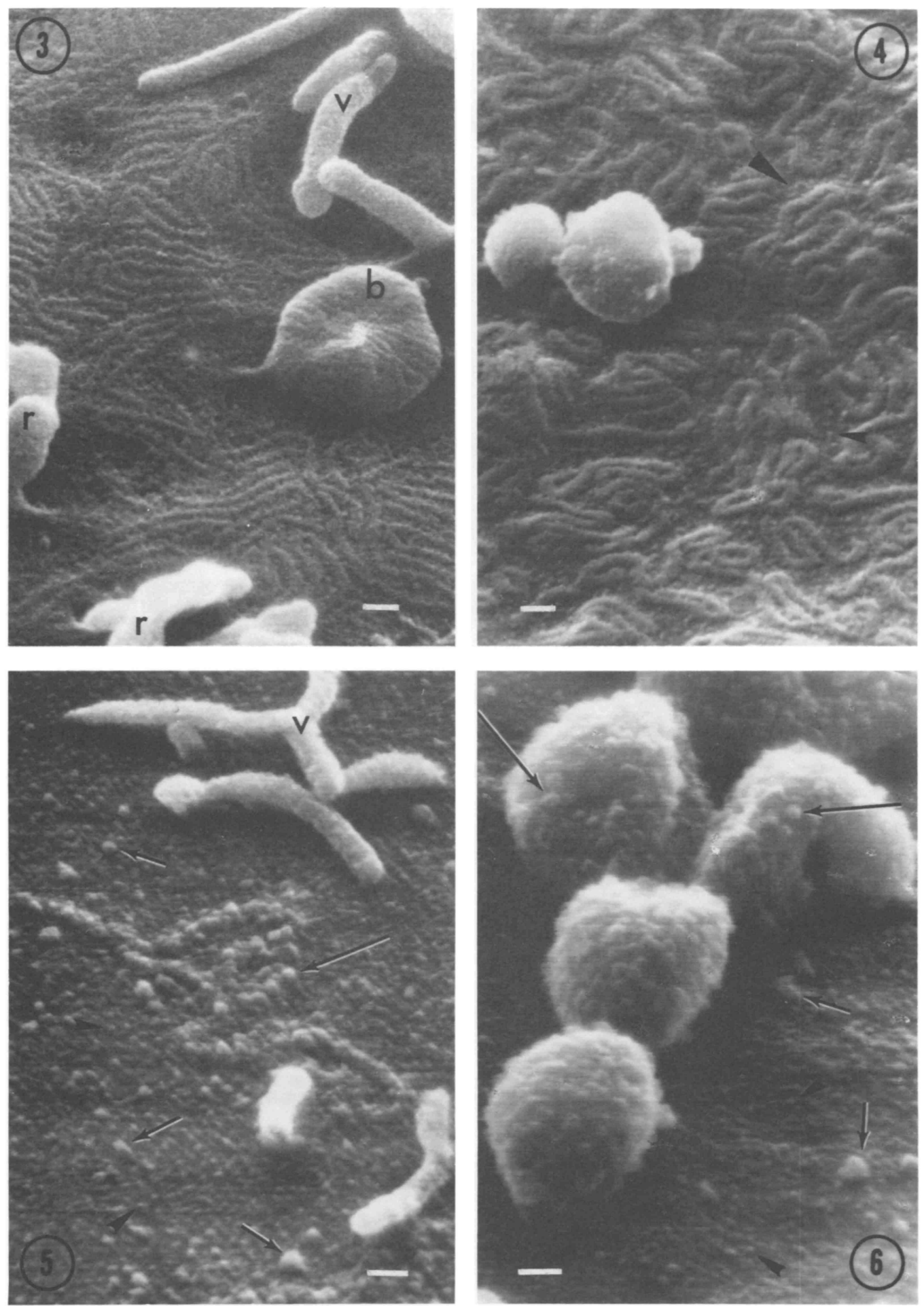

FIG. 3 to 6. Details of giant cell surface at a high magnification in the scanning electron microscope. Bar $=0.1 \mu \mathrm{m}$. In Fig. 3, the surface contains numerous thin ridges which are virus-induced structures overlying nucleocapsids. Ridges are aligned and coiled on one viral bud (b). v, Villi; r, ruffles. In Fig. 4, the center of a giant cell is covered with wide twisted ridges. Small granules (approximately $15 \mathrm{~nm}$ large) are present between ridges (arrowheads) and are also seen on the surface of uninfected cells. The two round bodies on the left are probably mature virions. In Fig. 5 and 6, after immunoperoxidase labeling of measles antigens, granules of specific label are scattered on the giant cell surface (short arrows) and can be distinguished from the background granules (arrowheads) which are smaller (Fig. 4). Numerous granules of label are clustered on a twisted ridge in Fig. 5 and on four viral buds in Fig. 6 (long arrows). To show an individual ridge (Fig. 5), the picture was taken in an area where ridges are less densely packed. 

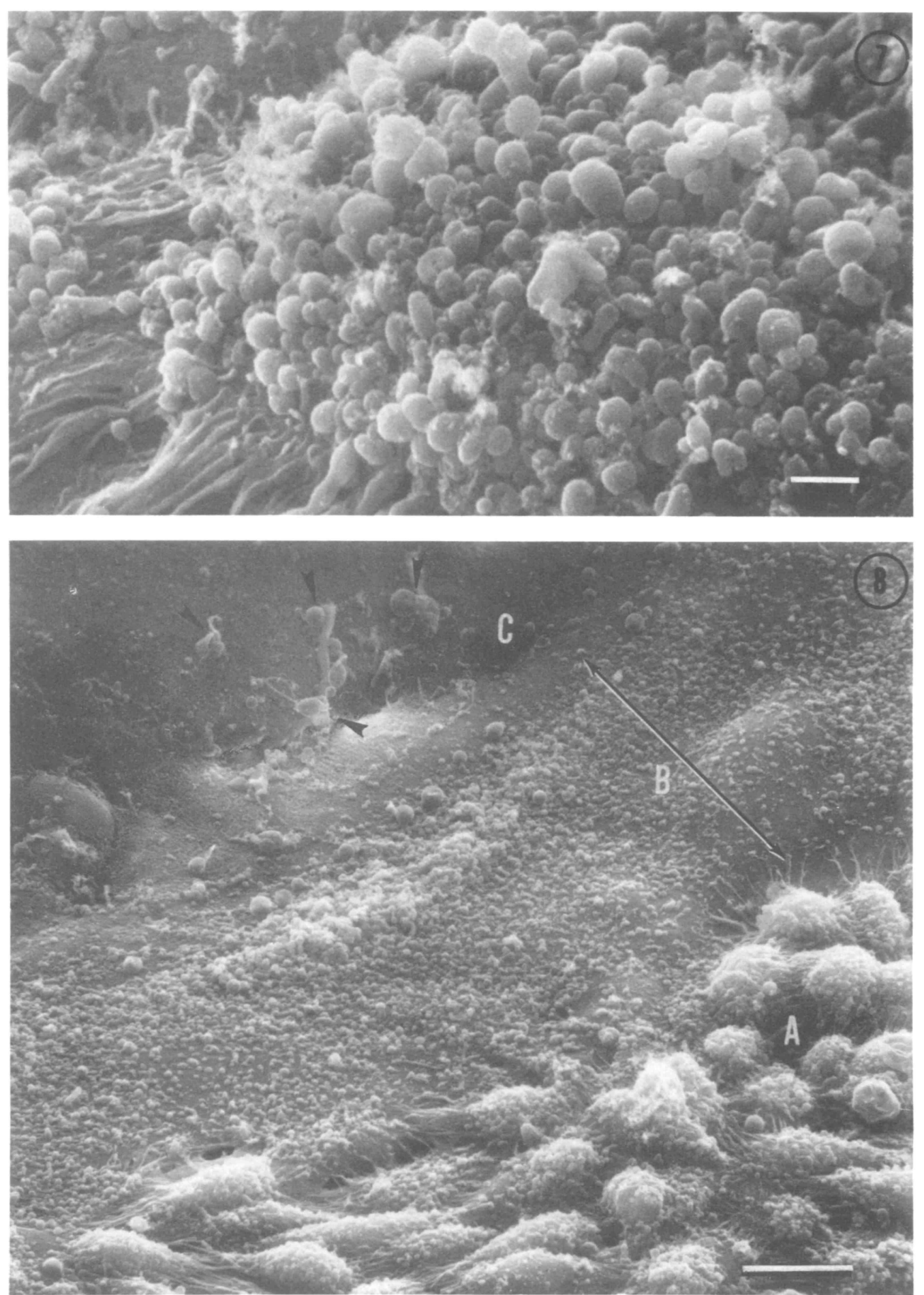

FIG. 7. Mononucleated cells covered with many viral buds of various sizes and shapes. Bar $=1 \mu \mathrm{m}$. FIG. 8. Overview of an area of the monolayer where fusion is progressing. At the bottom right, mononucle-ated cells (A) are loaded with viral buds as shown in Fig. 7. At the top left, the giant cell membrane (C) is almost free of viral buds. Note, however, the presence of large blebs (arrowheads) which are artifacts of fixation. In the area of ongoing fusion, a strip approximately $30 \mu \mathrm{m}$ wide (B) has recently fused with the rest of the giant cell and is covered with a large number of viral buds. Bar $=10$ $\mu m$. 

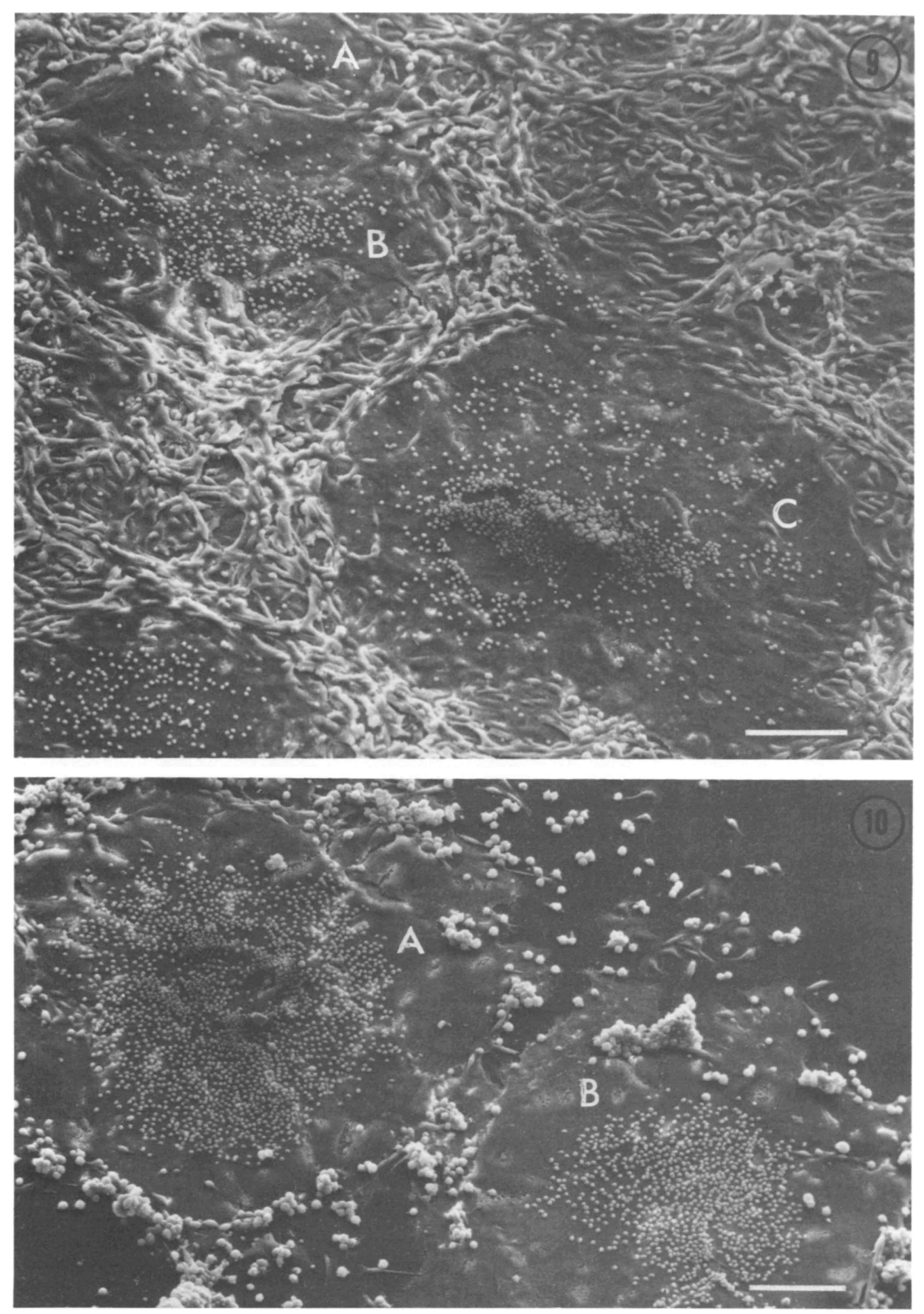

FIG. 9. HAD pattern on an infected cell monolayer. The RBC attachment is almost completely restricted to the syncytia. (A) Small syncytium with RBC scattered over its surface; (B) medium-sized syncytium with RBC scattered over its surface, but more numerous in the center; (C) mature syncytium with RBC clustered in the center. Bar $=100 \mu \mathrm{m}$.

FIG. 10. Two syncytia (A, mature; B, immature) after treatment of cultures with chymotrypsin (0.02 $\mathrm{mg} / \mathrm{ml}$ for $10 \mathrm{~min}$ ). Most of the mononucleated cells have been removed from the glass substrate. Under these conditions, RBC still absorbed to syncytia. The greatest density of RBC is centrally located on both giant cells, with clustering of hemadsorbing sites around the center in A (see also Fig. 11 and 12). Bar $=100 \mu \mathrm{m}$. 

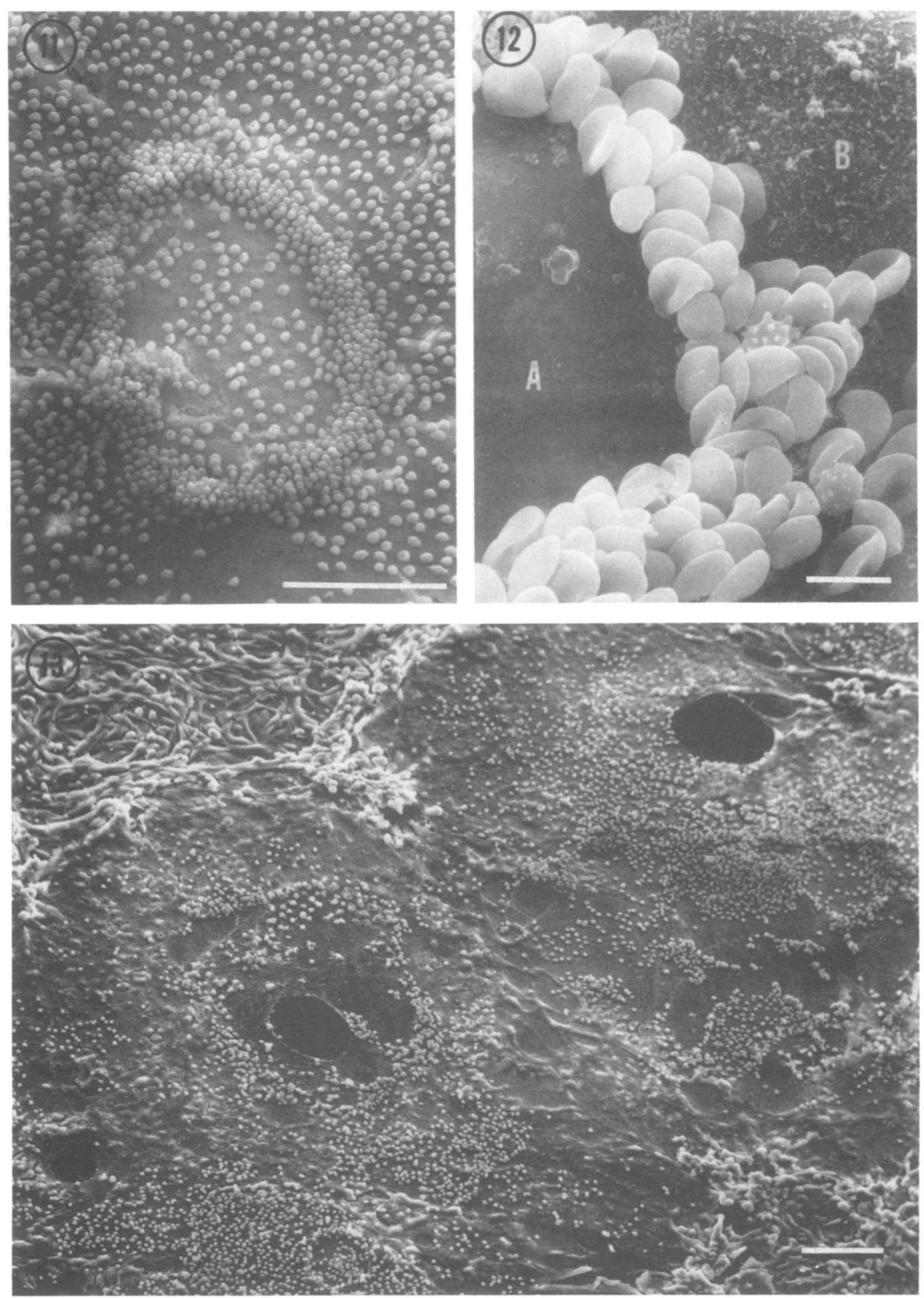

FIG. 11 to 13. Progressive loss of kemadsorbing sites in the center of mature syncytia. In Fig. 11, the central area bears fewer hemadsorbing sites than does the rest of the giant cell, and a ring of clustered $R B C$ is present around the center. Bar $=100 \mu \mathrm{m}$. In Fig. 12, the membrane of the central area $(A)$ is completely smooth and is surrounded by a sharply delineated ring of $R B C$. Outside this ring, the membrane shows scattered villi (B). Bar $=10 \mu \mathrm{m}$. In Fig. 13, holes have appeared in the central areas and are expanding toward the edges of the giant cells. Hemadsorbing sites are absent from large areas around these lytic areas. Bar $=100 \mu \mathrm{m}$. 

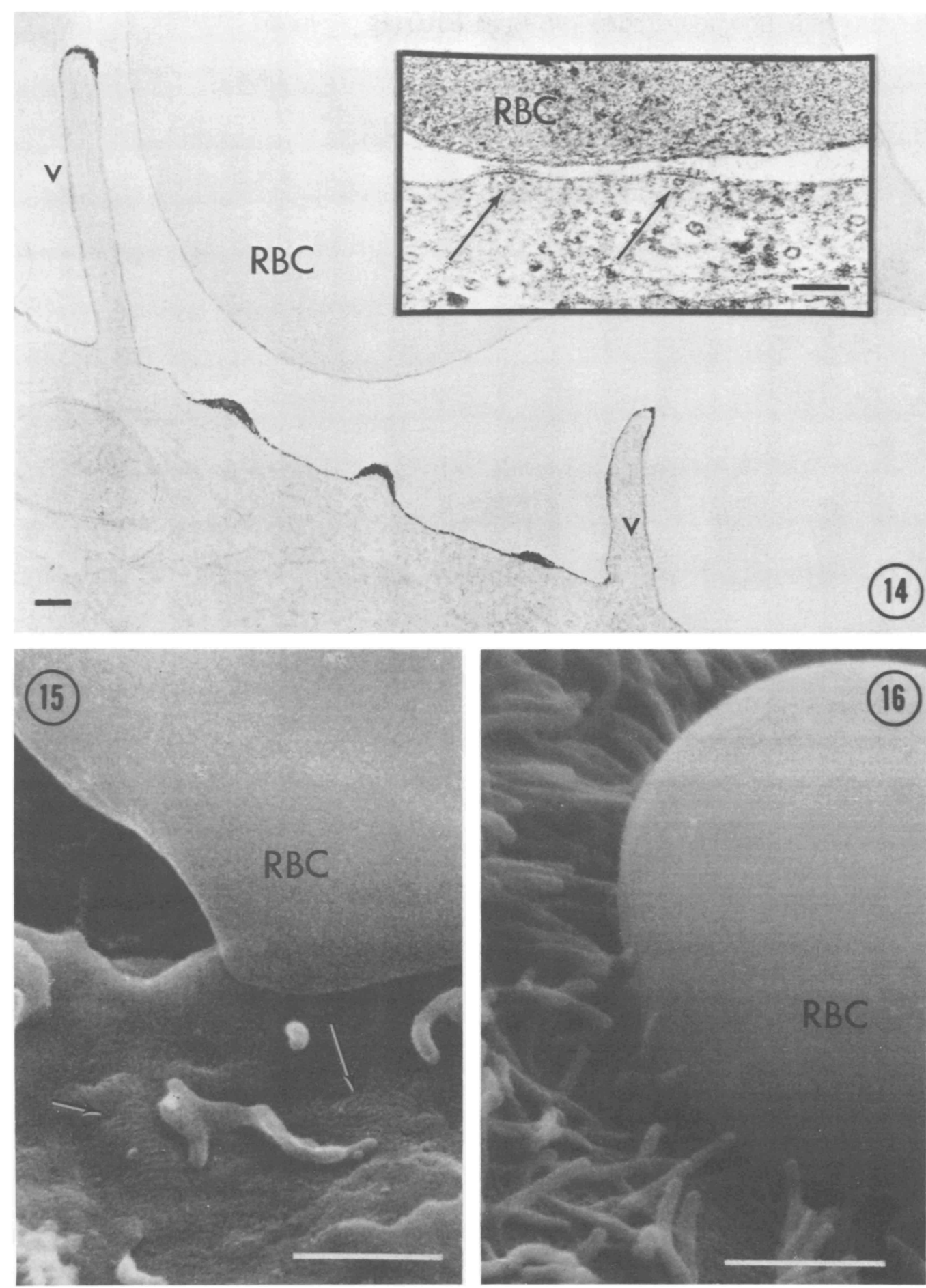

FIG. 14 to 16. Details of the hemadsorbing sites in transmission and scanning electron microscopes. Figure 14 shows a thin section through a giant cell first incubated with RBC and then immunolabeled for measles antigens. Patches of black label, found occasionally on ridges, are scattered on the membrane and at the ends of microvilli (v) (no counterstain with heavy salts). Bar $=0.1 \mu \mathrm{m}$. The inset shows a close contact between an RBC and two characteristic ridges (arrows) which are transversally sectioned and contain a nucleocapsid under spikes (no labeling in this preparation). Bar $=0.1 \mu m$. In Fig. 15, numerous ridges (arrows) were detected by SEM on the membrane adjacent to an adherent RBC. Bar $=1 \mu \mathrm{m}$. In Fig. 16, numerous microvilli adhere strongly to one RBC. Bar $=1 \mu \mathrm{m}$. 


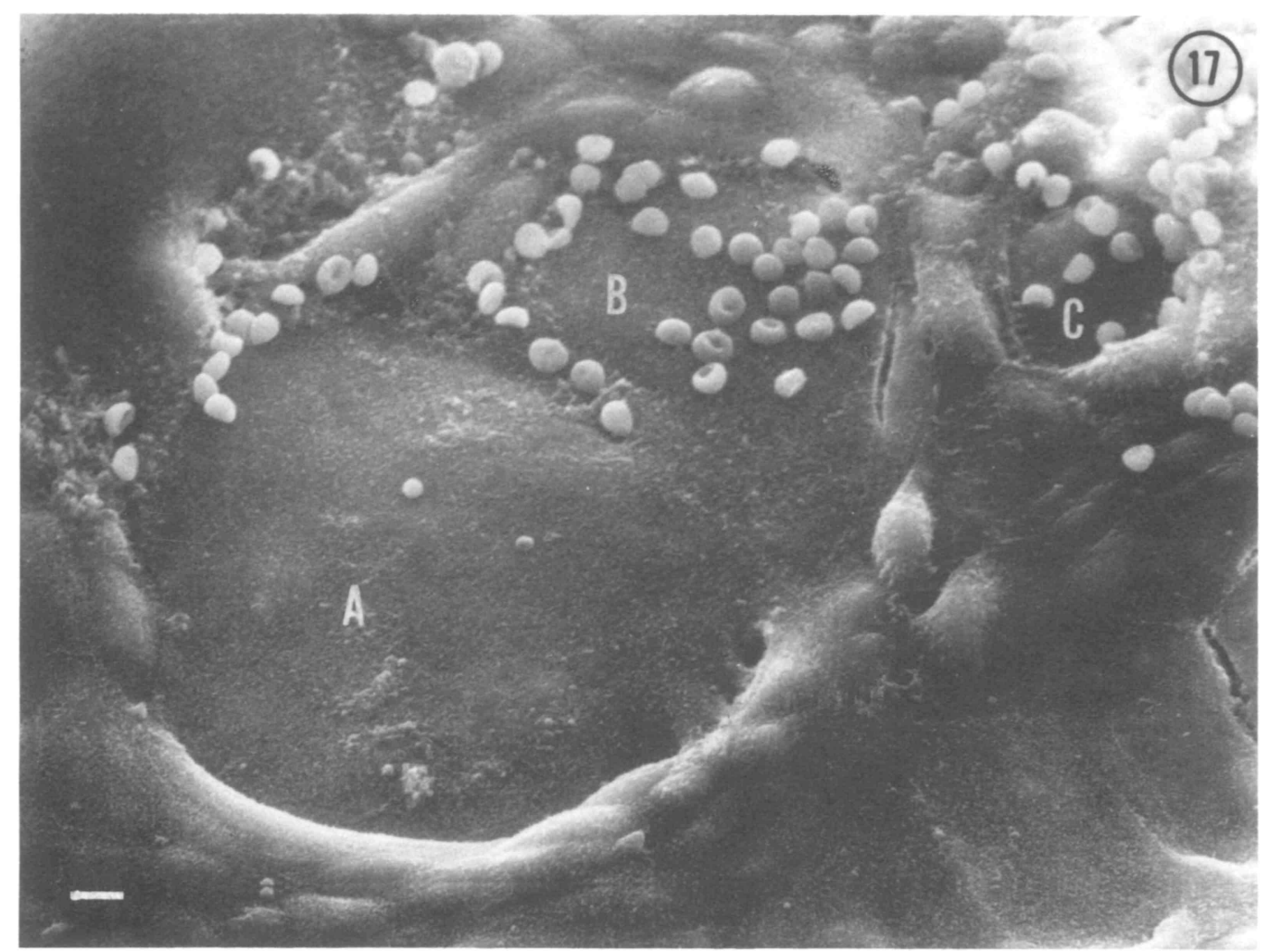

FIG. 17. After blocking of hemadsorbing sites by antimeasles $\operatorname{Ig} G$ at $4^{\circ} \mathrm{C}$, new binding sites were first detected at the edge of small syncytia after a 10-min incubation at $37^{\circ} \mathrm{C}$. Recovery of binding sites is correlated with syncytium size: hemadsorbing areas are seen on top of syncytium $A$ and at its junction with $B$, around $B$, and over $C$. Mature syncytia (400 $\mu \mathrm{m}$ and larger) do not recover HAD. Bar $=10 \mu \mathrm{m}$.

Treatment of infected cultures with proteases did not alter HAD. It appears that the binding sites are not sensitive to such a mild and short treatment or, if they are, that hemadsorbing sites are very rapidly reinserted in the plasma membrane, as has been observed with a chronically infected cell line [11]. This type of protease treatment could be useful for separating syncytia from mononucle-ated cells to analyze separately the composition of their plasma membranes and correlate it with complete or defective bud formation.

Virus-induced ridges and villi were the main structures seen in hemadsorbing sites. Indeed, TEM and SEM clearly showed that the attachment sites for RBC on membranes of measles virus-infected cells correspond to strands covering nucleocapsids as in mumps virus-infected chicken embryo cells [10]. In addition, hemad-sorbing sites and measles antigens were found on morphologically identical structures located on membranes. These structures were ridges and microvilli which adhered firmly to RBC. In our studies, no long cellular protrusions [15] or viral buds [14] were detected at the sites of HAD. RBC were always attached directly to the membrane of an infected cell, in agreement with observations in cells infected by other ortho- or paramyxoviruses $[5,10,14,15]$. In all experiments, RBC were almost spherical with SEM, but had a distorted shape with TEM. Thus, morphological changes in RBC thought to result from adsorption onto virus-infected cells [2] were probably an artifact of preparation for TEM.

The formation of a ring of clustered $\mathrm{RBC}$ around the center of all mature giant cells appeared to be caused by cell death. Inside the ring, the plasma membrane was flat and devoid of microvilli or ruffles. One interpretation would be that the center of the giant cell had lost its membrane fluidity so that RBC binding sites moving centripetally would accumulate around this central area. A similar ring has been observed after immunolabeling when antibodies were used to induce antigen redistribution on the surface of syncytia during measles virus infection (Hooghe-Peters, Rentier, and Dubois-Dalcq, submitted for publication).

It remains unclear why RBC rarely adsorbed to mononucleated cells covered with viral buds. Ridges which accumulated in the center of giant cells contained a high density of RBC receptors. These receptors clustered on flat surfaces might be more readily accessible for RBC interaction than receptors located on ridges scattered on other areas of syncytia and on virions budding from mononucleated 
cells. The HAD pattern-therefore, could reflect the structure, number, and accessibility of receptor sites, rather than their simple presence. The cause of the centripetal movement of receptors is unexplained. It could be triggered by the attachment of RBC to the cell membrane since sheep RBC can induce capping of their binding sites on lymphocytes [1). However, accumulation of ridges in the center of mature giant cells occurs in the absence of RBC.

In conclusion, field emission SEM has permitted the study of the interaction of RBC with large areas of measles virus-infected cell cultures and identified fine structural changes and labeled viral antigens on their surface. This study has shown that (i) viral maturation sites are numerous on mononucleated cells, but rare on giant cells which contain viral antigens and receptors for RBC, and (ii) HAD sites are located on giant cells and appear to move toward the center of giant cells while fusion is progressing. This suggests that free diffusion of the binding sites occurs within the plane of the giant cell membrane.

\section{Acknowledgments}

We are indebted to Maneth Gravell for his critical and extensive review of the manuscript. We also thank Thomas S. Reese, Dale E. McFarlin, and John L. Sever for their advice. We are grateful to Barbara Reese for her invaluable help with the SEM and to Sharon K. Painter for typing. B.R. and E.H.-P. are Visiting Fellows of the Fogarty International Center, and M.D.-D. is a Visiting Scientist at the National Institutes of Health.

\section{References}

[1]. Ashman, R, F. 1973. Lymphocyte receptor movements induced by sheep erythrocyte binding. J. Immunol. 111:212-220.

[2]. Baker- R., I. Gordon, and D. Stevenson. 1965. Electron microscope study of hemadsorption in measles virus infection. Virology 27:441-445.

[3]. BerkalofT, A., and L. Colobert. 1963. Modification de rultrastructure de la membrane cytoplasmique des cellules de rein de veau infectees par Myxovirus influenzae B (Souche Lee). J. Microsc. (Paris) 2:57-70.

[4]. Bratt, M. A., and W. R. Gallaher. 1969. Preliminary analysis of the requirements for fusion from within and fusion from without by Newcastle disease virus. Proc. Natl. Acad. Sci. U.S.A. 64:538-543. [5]. Compans, R. W., D. H. Harter, and P. W. Choppin. 1967. Studies on pneumonia virus of mice (PVM) in cell culture. II. Structure and morphogenesis of the virus particle. J. Exp. Med. 126:267-276. [6]. Dubois-Dalcq, M., and L. H. Barbosa. 1973. Immuno- peroxidase stain of measles antigen in tissue culture. J. Virol. 12:909-918.

[7]. Dubois-Dalcq, M., L. H. Barbosa, R. Hamilton, and J. L. Sever. 1974. Comparison between productive and latent subacute sclerosing panencephalitis viral infection in vitro. An electron microscopic and immunope-roxidase study. Lab. Invest. 30:241-250.

[8]. Dubois-Dalcq, M., H. McFarland, and D. McFarlin. 1977. Protein A-peroxidase: a valuable tool for the localization of antigens. J. Histochem. Cytochem. 25:1201-1206.

[9]. Dubois-Dalcq, M., and T. S. Reese. 1975. Structural changes in the membrane of Vero cells infected with a paramyxovirus. J. Cell Biol. 67:551-565.

[10]. Due-Nguyen, H. 1968. Hemadsorption of mumps virus examined by light and electron microscopy. J. Virol. 2:494-506.

[11]. Ehrnst, A., and K.-G. Sundqvist. 1975. Polar appearance and nonligand induced spreading of measles virus hemagglutinin at the surface of chronically infected cells. Cell 5:351-359.

[12]. Graham, R. C, and M. J. Karnovsky. 1966. The early stage of absorption of injected horseradish peroxidase in the proximal tubules of mouse kidney: ultrastructural cytochemistry by a new technique. J. Histochem. Cytochem. 14:291-302.

[13]. Holmes, K. V., and P. W. Choppin. 1966. On the role of the response of the cell membrane in detennining virus virulence: contrasting effects of the parainfluenza virus SV5 in two cells types. J. Exp. Med. 124:501-520.

[14.] Hotchin, J. E., S. M. Cohen, H. Rußka, and C. Ruska. 1958. Electron microscopical aspects of hemadsorption in tissue culture infected with influenza virus. Virology 6:684-701.

[15]. Mannweiler, K., and G. Rutter. 1975. High resolution investigations with the scanning and transmission electron microscope of hemadsorption binding sites of mumps virus-infected HeLa cells. J. Gen. Virol. 28:99-109.

[16]. Marcus, P. 1.1962. Dynamics of surface modifications in Myxovirus infected cells. Cold Spring 
Harbor Symp. Quant. Biol. 27:351-365.

[17]. Morgan, C, K. C. Hßu, R. A. Rifkind, A. W. Knox, and H. M. Rose. 1961. The application of ferritin conjugated antibody to electron microscopic studies of influenza virus in infected cells. I. The cellular surface. П. The interior of the cell. J. Exp. Med. 114:825-836.

[18]. Morgan, C, R. A. Rifkind, and H. M. Rose. 1962. The use of ferritin conjugated antibodies in electron microscopic studies of influenza and vaccinia virus infected cells. Cold Spring Harbor Symp. Quant. Biol. 27:57-61.

[19]. Peries, J. R., and C. Chany. 1960. Activite hemagglutinante du virus morbilleux. C.R. Acad. Sci. 251:280-821.

[20]. Rentier, B., and M. Dubois-Dalcq. 1977. Structural basis of hemadsorbing sites during the formation of syncytia in measles infected cells. J. Cell Biol. 75:396a.

[21]. Rosen, L. 1961. Hemagglutination and hemagglutination-inhibition with measles virus. Virology 13:139-141.

[22]. Sober, H. A., F. J. Gutter, M. M. Wyckofif, and E. A. Peterson. 1956. Chromatography of proteins. II. Fractionation of serum proteins on anion exchange cellulose. J. Am. Chem. Soc. 78:756763.

[23]. Vogel, J., and A. Shelokov. 1957. Adsorption-hemagglutination test for influenza virus in monkey kidney tissue cultures. Science 126:358-359. 